\title{
Eastern Europe decries EU research proposal
}

Quirin Schiermeier, Linköping, Sweden

Proposed changes to the structure of the research programme run by the European Union (EU) could torpedo the efforts of central and eastern European countries to increase their participation, scientists and policy-makers warned last week.

Most of the EU's research activities are organized into five-year 'Framework' programmes. Until now, these have supported large numbers of relatively small projects, creating networks that link scientists from several EU member states - and nations that have 'association' agreements with Brussels.

But the European Commission plans to shake up the 17.5-billion-euro (US\$15 billion) sixth Framework, scheduled to start in 2003. Research commissioner Philippe Busquin wants to focus on larger, integrated projects (see Nature 410, 4; 2001). And he intends to delegate the management of each project to one of the research centres involved.

Researchers from the 11 'candidate' nations waiting to join the EU believe these changes will favour countries that already have a strong science base. Their complaints spilled over last week in Linköping, Sweden, at a meeting held to discuss the role of the candidate countries in EU research.

Bulgaria, the Czech Republic, Cyprus, Estonia, Hungary, Latvia, Lithuania, Poland, Romania, Slovakia and Slovenia are all scheduled to join the EU in the next few years - and scientists from these countries are already eligible for funding under the fifth Framework. Each candidate country pays an entrance fee calculated according to its gross domestic product and spending on research.

Even under the existing system, researchers from candidate countries have found it difficult to compete for funding. Poland estimates that its scientists have recouped only 60 million euros of its entrance fee of 160 million euros.

"We expected a mountain of gold in Brussels just waiting for us to go and fetch it," says Andrzej Siemaszko, who heads the government office in Warsaw that helps Polish scientists write EU project proposals. But given low success rates, "it is getting increasingly difficult to convince people to spend three months on preparing an application", he says.

The new Framework proposals are expected to widen the gap between the candidate countries' investment and their returns. If this happens, some observers fear that these countries may withdraw from their association agreements - dealing a serious blow to prospects for greater European cooperation in research.

"It took us more than two years to acquire the skills needed to write a good proposal," Uros Stanic, an electronics engineer at the Josef Stefan Institute in Ljubljana, told last week's meeting. "The switch to a completely new terminology and new funding instruments will force us to start from scratch."

Last month, Poland, the Czech Republic, Slovakia, Slovenia and Hungary called on the European Commission to involve more representatives of candidate countries in preparing the sixth Framework, and to reconsider the balance between small and large-scale projects.
EU officials deny that the integrated projects will exclude scientists from the candidate countries. "They do not necessarily require lots of expensive infrastructures and equipment," says Hendrik Tent, deputy director of the commission's research directorate. "They can also be clusters of smaller projects designed to meet one coherent objective."

But the commission is trying to address the candidate countries' concerns. It plans to spend 40 million euros on moves to encourage contacts between their scientists and those in EU member states, and is also planning a series of 'information days' to explain funding procedures.

ittp://europa.eu.int/comm/research/nfp.html

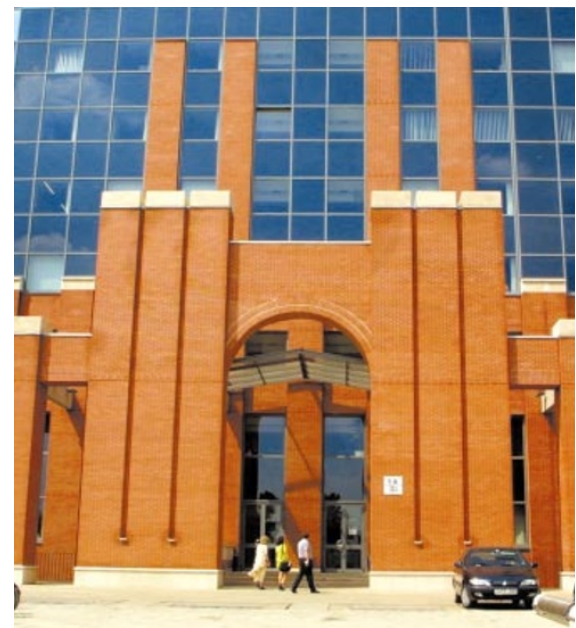

Researchers at Budapest's Eötvös University are among those who fear they may be excluded.

\section{Astronomers find fast-food plans hard to swallow}

Sally Goodman, Paris

Astronomers at France's Pic du Midi

observatory in the Pyrenees claim that plans

to open a fast-food restaurant at the site will

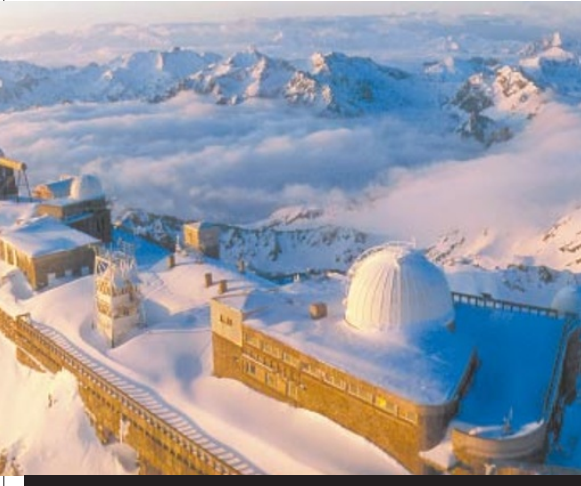

Cold shoulder: astronomers at Pic du Midi say greasy fumes could ruin their research. have disastrous effects on their research.

François Colas and Jean Lecacheux of the Paris Observatory, who use a 1-metre telescope at Pic du Midi to study comets and planetary systems, have launched a petition to stop the development. They say that hot air and greasy fumes will damage the telescope's mirror - which is situated just 15 metres above the planned restaurant.

Ironically, the observatory was saved from closure in 1998 through a scheme to develop the site for tourism, after the French government threatened to withdraw funding from telescopes less than 2 metres in diameter. Until now, astronomers have stoically accepted the changes. But the fast-food restaurant plan, hatched by regional and local authorities, is "the last straw", says Colas.

The situation is symptomatic of the plight of observatories operating small telescopes, whose futures are threatened by the proliferation of telescopes with mirrors larger than 8 metres across. These huge facilities consume the lion's share of most national astronomy budgets (see Nature 408, 12-15; 2000).

But there is still valuable science to be done with small telescopes, argues Gerry Gilmore of the University of Cambridge, who chairs OPTICON, the Optical Infrared Coordination Network, an initiative funded by the European Union.

"It is often not cost-effective to do specialized experiments on the very large telescopes," Gilmore says. Projects that need repeated observations of objects, for instance, usually cannot get time on big telescopes. Smaller telescopes also play a vital role in training, he adds. 